\title{
Verification! Predicted Information Provided from SPEEDI during the Fukushima Daiichi Nuclear Accident
} -Accuracy, Timeliness, and Future Utilization-

\author{
Japan Atomic Energy Agency, Masamichi Chino
}

\begin{abstract}
In swift response to the accident that occurred at TEPCO's Fukushima Daiichi Nuclear Power Plant, SPEEDI has been providing information to relevant agencies in accordance with the established manual. A failure to take this information into account when decisions were taken regarding evacuations and other measures caused considerable controversy. This commentary examines the types and timing of the predicted information that SPEEDI provided during the accident. It then verifies the accuracy of the predictions through a comparison with the monitoring data obtained from actual measurements before considering future utilization of SPEEDI.
\end{abstract}

\section{Introduction}

SPEEDI facilitates preparations for a massive release of radioactive materials from nuclear power plants or elsewhere by quickly predicting the atmospheric concentration of the radioactive materials and the exposure dose in the surrounding environment through computer simulations.

The Investigation Committee on the Accident at the Fukushima Nuclear Power Plants of Tokyo Electric Power Company (ICANPS), the Independent Investigation Commission on the Fukushima Daiichi Nuclear Accident, and the report published by the Japanese government for the IAEA Ministerial Conference on Nuclear Safety all concluded that SPEEDI should have been proactively employed for the evacuation measures implemented in response to the nuclear accident at the Fukushima Daiichi Nuclear Power Plant. However, the National Diet of Japan Fukushima Nuclear Accident Independent Investigation Commission (NAIIC) concluded that the computational predictions produced by SPEEDI had limited usefulness in relation to making decisions on evacuation measures and that it is necessary to reinforce emergency monitoring measures instead.

To deepen this discussion, it is essential that we examine some basic points. First, what types of predicted information did SPEEDI provide in relation to this accident and when was such information provided to the relevant agencies? Second, how accurate was this information in comparison to the monitoring data that was subsequently obtained? On September 21,

DOI : 10.15669/fukushimainsights.Vol.2.22

(C) 2021 Atomic Energy Society of Japan. All rights reserved.

Originally published in Journal of the Atomic Energy Society of Japan (ISSN 1882-2606), Vol. 55, No. 4, p. 220-224 (2013)

in Japanese. (Japanese version accepted: February 8, 2013) 
2012, the prefectural government of Fukushima published on its website data obtained from environmental monitoring posts within a range of $30 \mathrm{~km}$ from the Fukushima Daiichi Nuclear Power Plant, where sheltering and evacuation measures were conducted ${ }^{1)}$. To some extent, this data made it possible to keep track of temporal and spatial changes in the air dose rate within this range.

This commentary examines the results of the predictions provided by SPEEDI and the timing of their provision to the Ministry of Education, Culture, Sports, Science and Technology (MEXT) and the now defunct Nuclear and Industrial Safety Agency (NISA). These predictions were later uploaded to their respective websites. The commentary then discusses the timeliness and accuracy of the information provided to the relevant agencies by SPEEDI. Based on the author's findings, possible future utilization for SPEEDI is explored.

\section{Types, Accuracy, and Timeliness of the Data Provided by SPEEDI}

The predicted information provided by SPEEDI can be roughly divided into the results of either regular predictions or on-demand predictions.

Regular predictions are made by assuming that the release of a unit amount $(1 \mathrm{~Bq} / \mathrm{h})$ of radioactive materials begins every hour on the hour to present the hourly movements of radioactive plumes in the form of the air dose rate distribution and the like. During the Fukushima Accident, regular predictions were commenced at 4 p.m. on March 11, 2011, to provide information to the relevant agencies every hour on the hour. Initially, the distribution was predicted up to 2 hours later within a range of $25 \times 25 \mathrm{~km}^{2}$. As the contaminated areas grew, this range was expanded to $100 \times 100 \mathrm{~km}^{2}$, starting from 8 a.m. on March 16. At that point, predictions were made up to 3 hours later.

On-demand predictions are conducted under the conditions specified by NISA's Emergency Response Center (ERC) and Off-site Center (OFC), the now defunct Nuclear Safety Commission (NSC), and other such bodies to assess the environmental impact of escalating events, plan emergency environmental monitoring, inversely estimate the amount of radioactive materials released, and assess the dose based on the estimated amount of release.

This commentary first examines the ability of SPEEDI to predict the movements of the radioactive plumes based on the results obtained from regular predictions and identifies the weather conditions that caused a reduction in accuracy. Subsequently, the accuracy and timeliness of the information provided are examined based on on-demand predictions, such as the prediction of the impact of the venting and the hydrogen explosion requested by the ERC as well as the prediction of the dispersion requested by the OFC to plan emergency monitoring measures. The examination period mainly covers March 11 to 16 when information was frequently provided to the ERC, OFC, and other such bodies.

\section{Characteristics during the Examination Period Described from the Observation Data}

The examination begins with an overview of the movements of the radioactive plumes from March 11 to 16 using data obtained from various monitoring posts in Fukushima Prefecture. The distribution of these monitoring posts is represented by small circles in Figure 1. On this map, the location names are indicated by the posts mentioned in the 


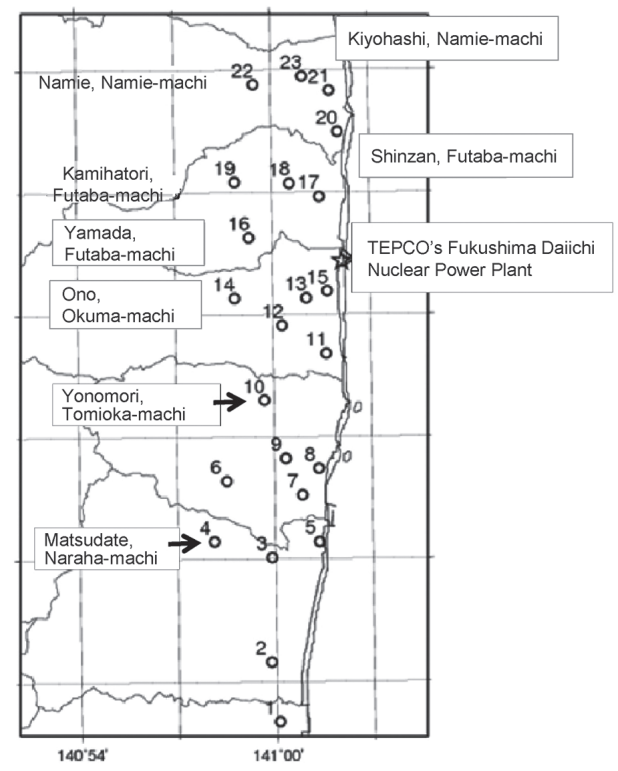

Figure 1 Locations of monitoring posts

commentary.

March 12: Beginning in the morning, increases in the air dose rate of up to $30 \mu \mathrm{Sv} / \mathrm{h}$ were observed at several posts. These increases are probably associated with leaks from the primary containment vessel. The major atmospheric release is believed to have taken place in the afternoon from 14:30 to 15:00 when the drywell pressure dropped sharply as a result of the venting conducted at Unit 1 . The increase in the air dose rate to $1,590 \mu \mathrm{Sv} / \mathrm{h}$ that was observed at 3 p.m. in Kamihatori, Futaba-machi (5.6 km northwest (NW), and the subsequent reduction in the dose rate on the ground surface to $30 \mu \mathrm{Sv} / \mathrm{h}$ by March 15 are probably associated with the plume produced by a wet venting with a large amount of noble gases and a relatively small amount of iodine and cesium. At 15:36, Unit 1 experienced a hydrogen explosion. At 5 p.m. in Shinzan, Futaba-machi (3.9 km NNW), the air dose rate increased to 904 $\mu \mathrm{Sv} / \mathrm{h}$. In contrast to the case in Kamihatori, the dose rate on the ground surface had only declined to around $200 \mu \mathrm{Sv} / \mathrm{h}$ by March 15 after the plume passed over that area. Considering the observed wind direction, the increase in the dose rate can be ascribed to the hydrogen explosion.

March 13-14: On March 13, the pressure of the drywell increased and venting was performed several times at Unit 3. Temporary increases in the air dose rate of up to a few dozen $\mu \mathrm{Sv} / \mathrm{h}$ were observed at several posts along the coast. However, the significant increases that had been observed in the previous afternoon did not occur because the plumes were carried seaward due to the weather conditions. On March 14, venting was performed at Unit 3, which subsequently experienced a hydrogen explosion. However, the weather conditions continued to carry the plumes seaward until the evening. At night, the dose rate began to increase in the area to the south of the site.

March 15-16: From about 7 to 8 a.m. on March 15, the dose rate began to increase to $41 \mu \mathrm{Sv} / \mathrm{h}$ in Yonomori, Tomioka-machi (7.3 km SSW), and to $19 \mu \mathrm{Sv} / \mathrm{h}$ in Matsudate, Naraha-machi (14.2 km SSW), both of which are located to the south of the Fukushima Daiichi Nuclear Power Plant. The posts that observed these increases shifted in a clockwise direction over time. At around 11 a.m., the post in Ono, Okuma-machi (4.9 km WSW), 
registered $390 \mu \mathrm{Sv} / \mathrm{h}$, which was followed by an increase to $232 \mu \mathrm{Sv} / \mathrm{h}$ in Yamada, Futabamachi (4.1 km WNW), at 1 p.m. and an increase to $32.1 \mu \mathrm{Sv} / \mathrm{h}$ in Namie, Namie-machi $(8.6 \mathrm{~km} \mathrm{NNW})$, at 9 p.m. By then, the flow of plumes had reversed from clockwise to counterclockwise. As a result, the dose rate increased again in Yamada, Futaba-machi, to 1,020 $\mu \mathrm{Sv} / \mathrm{h}$ at 0 a.m. on March 16. Subsequently, the post in Ono, Okuma-machi, registered $173 \mu \mathrm{Sv} / \mathrm{h}$ at 1 a.m. and the measurement in Matsudate, Naraha-machi, peaked at $44.5 \mu \mathrm{Sv} / \mathrm{h}$ at $3 \mathrm{a} . \mathrm{m}$. After that, the plumes probably flowed seaward in a south-southeast direction. After the dose rate increased between 11 and 12 a.m. on March 16 in Matsudate, Naraha-machi (33 $\mu \mathrm{Sv} / \mathrm{h})$, and in Ono, Okuma-machi $(324 \mu \mathrm{Sv} / \mathrm{h})$, the plumes are believed to have travelled seaward until the morning of March 20.

Due to space limitations, this commentary cannot present an examination of all of the plumes. Instead, it will examine the predictions made for the afternoon of March 12 and a period covering March 15 to 16, when major increases in the dose rates were observed onshore.

\section{Accuracy of Regular Predictions ${ }^{2)}$}

Figure 2 presents the results of regular predictions that assume a release at 2, 3, and 4 p.m. on March 12 with the venting taking place between 14:30 and 15:00 as well as the hydrogen explosion (15:36). The predictions chronologically present the air-absorbed dose rates 2 hours after the release. On March 12, the wind direction shifted clockwise from about noon. The increase in the dose rate in Kamihatori, Futaba-machi, at 3 p.m. caused by venting is reproduced by the predicted plume (figure in the center) from the release at 3 p.m. with a lag of 1 to 2 hours. The movement of the plume from the hydrogen explosion is predicted almost accurately by the predicted plumes from the release at 3 and 4 p.m. (figures in the center and on the right), which reached Shinzan, Futaba-machi, and Namie, Namie-machi when the dose rates increased at 5 p.m.

Figure 3 shows the results of regular predictions produced by SPEEDI that were released on March 15 and 16. They present the distribution 2 hours after the release every hour on the hour from 8 a.m. on March 15, when the increase began, until 2 p.m. on March 16 with an interval of 6 hours. The result indicating that the flow of the predicted plume to the south-southwest direction at 8 a.m. on March 15 changed clockwise shows a similarity to the observation. At 2 p.m., the plume reached between Ono, Okuma-machi, and Yamada, Futaba-machi. The prediction lags about 2 hours from the actual movement. At 8 p.m., the predicted plume passed near Namie, which almost coincides with the actual observation. After that, the movement reversed at around 2 a.m. on March 16 to pass near Yamada, Futaba-machi, with lags of about 2 to 3 hours from the actual observation. Although this is not shown in the figure, the lag was compressed by the time the plume reached Matsudate, Naraha-machi, before moving offshore at 8 a.m. The plume predicted at 2 p.m. reproduced the temporal increase in the dose rate in the southwest with a time lag of about 2 hours. This plume later moved offshore. Here, the figure corresponding to the period from 1 to $2 \mathrm{p} . \mathrm{m}$. on March 16 presents a broader area in accordance with the expanded range of computation. The black-rimmed circles represent a range of $30 \mathrm{~km}$ from the center of the site.

On March 12, 15, and 16, the wind directions changed abruptly in a complex manner. However, the abovementioned results demonstrate that SPEEDI managed to provide a spatial-temporal overview of the movements of the radioactive plumes over time if we allow for a time lag of a few hours. The ICANPS report concluded that the predictions produced by SPEEDI for the north-west of the site could have been applied in deciding the timing of the sheltering on March 15 and the evacuation on March 16. The predictions were probably 
accurate enough for such an application.

Examples were not presented for March 13 and 14 because the plumes had moved offshore, making verification impossible. Nevertheless, SPEEDI also provided some useful information for these 2 days considering the successful prediction of the temporal increase in the coastal area and no major increases in the inland area.

Meanwhile, reduced accuracy was observed in some cases. From dawn throughout the rest of the morning on March 12 and 13, the release probably took place near the ground under almost calm weather conditions. With no definite wind directions, relatively small increases in the dose rate were observed in various directions near the site. Such a situation could not be properly predicted.
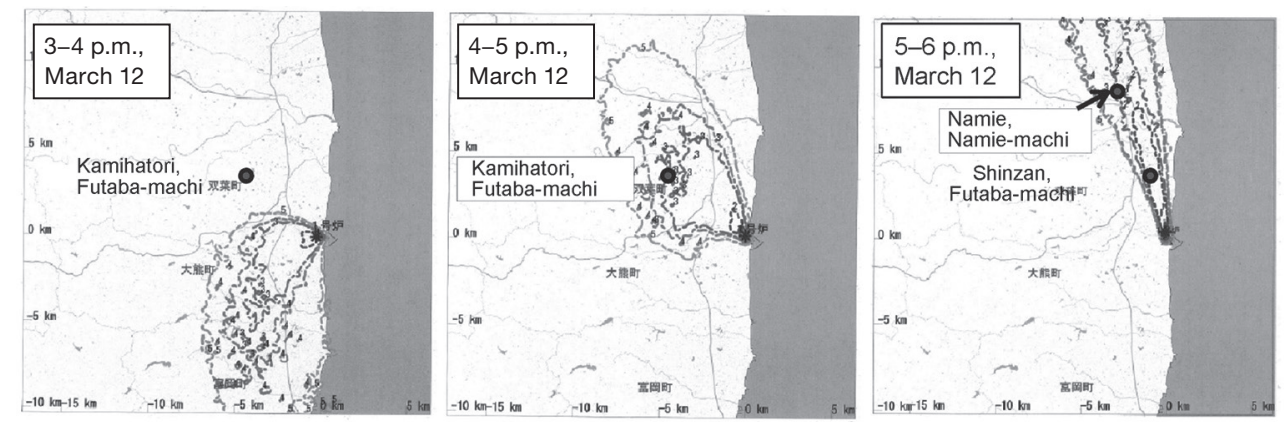

Figure 2 Regular predictions for the distribution of the air-absorbed dose rate 2 hours after the releases at 2, 3, and 4 p.m. on March 12

Source: http://www.bousai.ne.jp/speedi/20110312 rok/20110312.html
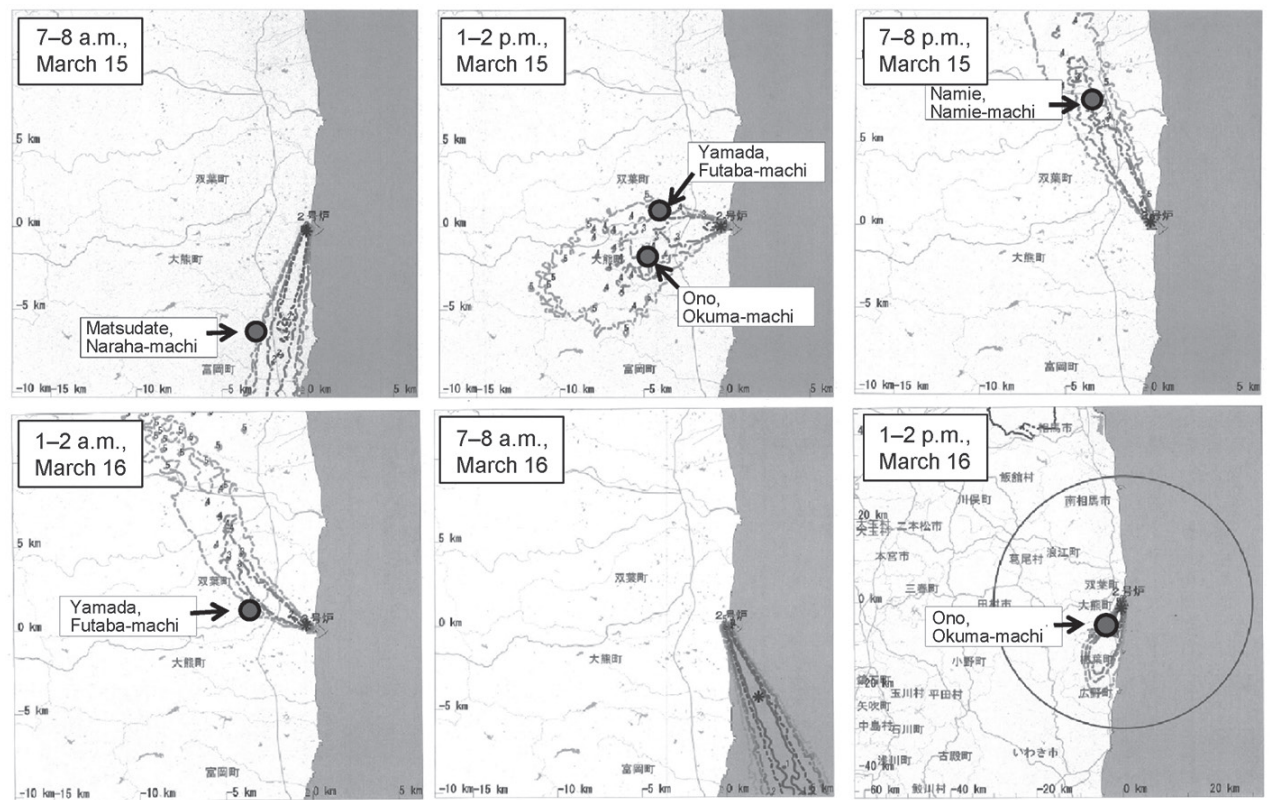

Figure 3 Regular predictions for the distribution of air-absorbed dose rate from March 15 to 16 Source:

March 15 http://www.bousai.ne.jp/speedi/20110315 rok/20110315.html March 16 http://www.bousai.ne.jp/speedi/20110316 rok/20110316.html 
In conclusion, SPEEDI should be utilized in predicting the arrival of a plume while allowing for certain margins of spatial-temporal error rather than expecting pinpoint information in terms of time and space. Margins of error depend on weather conditions and other factors. Accordingly, the predicted results should be adjusted in real time based on measurement data with a proper understanding of the relationship between SPEEDI's accuracy and weather conditions.

\section{Accuracy and Timeliness of On-Demand Predictions}

\section{(1) On-demand predictions for the $\mathrm{ERC}^{3)}$}

As no information on releases was available during the accident, the absolute values of the predictions produced by SPEEDI were not particularly meaningful. This commentary evaluates the predicted relative impact distribution.

Venting at Unit 1 on March 12: Prior to the venting conducted at Unit 1 from 2 p.m., the ERC requested on-demand predictions to check the impact by the venting. They received the results by 13:42. SPEEDI transmitted the distribution of the effective dose rate due to external exposure 3 hours after the release, as shown in Figure 4 (a). The distribution corresponding to the venting from 2 p.m. may be slightly displaced in a southward direction because the pressure dropped at around 14:30, which is believed to be when the release actually began. However, SPEEDI successfully predicted the dose increase in the direction toward Kamihatori, Futaba-machi, which actually experienced the increase at 3 p.m. This demonstrates that the predictions produced by SPEEDI can offer an effective means of determining the range of impact prior to a planned release (e.g., venting).

Hydrogen explosion at Unit 1 on March 12: Following the hydrogen explosion that occurred at 15:36, the ERC requested computational predictions to assess the impact. They received the results by 16:49. For some unknown reason, the starting time for the release was set to 5 p.m. for the prediction. SPEEDI transmitted the distribution of the effective dose rate due to external exposure 3 hours after the release, as shown in Figure 4 (b). The prediction was provided with a sufficient degree of accuracy before the dose rate really increased in the direction of Namie-machi at 5 p.m. and in the direction of Minamisoma between 7 and 8 p.m. During the event, no environmental monitoring data was available, but the predictions produced by SPEEDI could have facilitated decision-making with respect to sheltering or other precautionary measures against risks associated with the massive release resulting from the hydrogen explosion.

Massive release on March 15: Following the sound of the explosion that was heard at around 6 a.m. on March 15, the ERC requested computational predictions to assess the impact of the damage that was assumed to have occurred at the suppression chamber of Unit 2. They received the results at 6:51. SPEEDI transmitted the distribution of the deposition of iodine on the ground surface over a period of 24 hours starting from 9 a.m. on March 15, as shown in Figure 4 (c). Figure 4 (c) demonstrates that SPEEDI had already predicted in the morning of the same day the level of ground surface contamination that would exist in the northwest area in the evening. At the site boundary, a high dose had been recorded since early morning on March 15. If there were concerns that the contamination might continue until the evening, there should have been sufficient time to make the necessary precautionary decision for the public in the northwest area.

Compared to regular predictions, on-demand predictions produce a better match with the actual measurements. This is because they require the amount of cumulative deposition and the dose distribution to assess the dose impact and, consequently, spatial-temporal errors are 

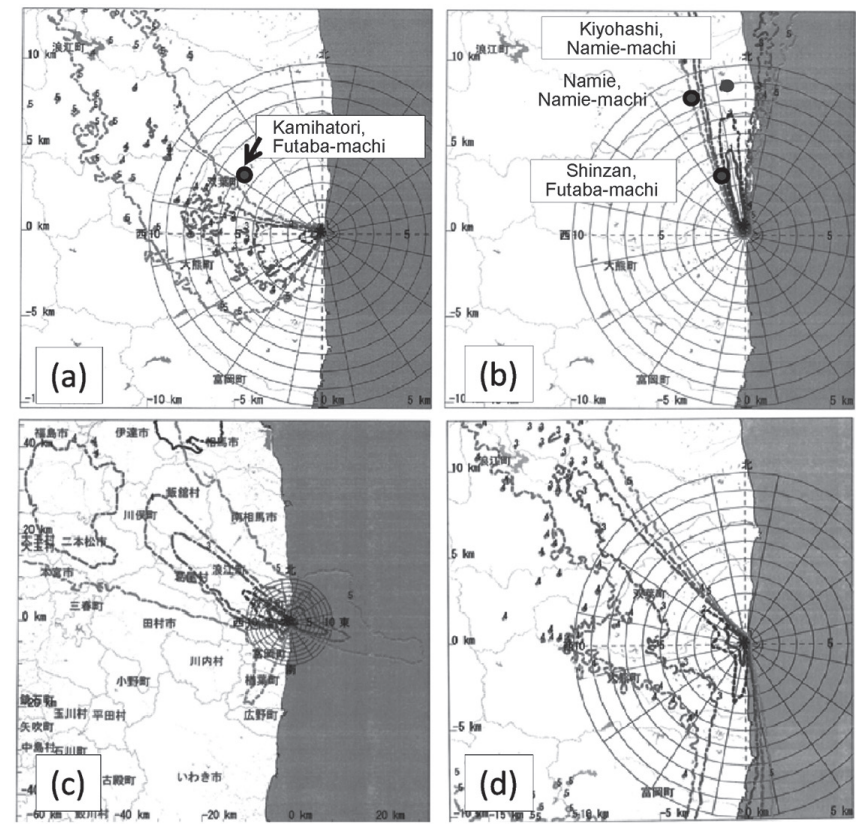

Figure 4 Examples of on-demand predictions

(a) Predicted impact of the venting on March 12 between 2 and 3 p.m.

(b) Predicted impact of the hydrogen explosion on March 12 at 15:36

(c) Predicted impact after the sound of the explosion on March 15 at around 6 a.m.

(d) Predicted impact for the planning of monitoring on March 15

Source:

(a), (b), (c) http://www.nsr.go.jp/archive/nisa/earthquake/speedi/erc/speedi_erc_index.html

(d) http://www.nsr.go.jp/archive/nisa/earthquake/speedi/ofc/speedi_ofc_index.html

canceled out through integration. In contrast, these errors appear in regular predictions due to the need to predict temporal changes of the plume.

(2) On-demand predictions for the $\mathbf{0 F C}{ }^{4)}$

The OFC has been receiving 24-hour predictions produced by SPEEDI by assuming a daily release of a unit quantity from March 14 as reference for the planning of emergency monitoring. When systematic emergency monitoring was initiated on March 15, the OFC received the distribution map for the effective dose rate due to external exposure before dawn at 2:32 on the same day as that shown in Figure 4 (d). This figure predicts the increase in the dose rate to the south of the site from dawn until late morning and to the northwest of the site in the evening. The prediction almost matched the actual measurements. As evidence of the effective utilization of SPEEDI, the investigation report (Chapter 2) ${ }^{5)}$ published by MEXT mentions that the prediction produced by SPEEDI made it possible to immediately deploy a monitoring team to the northwest high-dose area. However, as information on the changing behavior of the plumes is also effective for enabling dust sampling to measure their atmospheric concentration, such predictions should also be provided by SPEEDI.

\section{(3) On-demand predictions for the now defunct $\mathrm{NSC}^{6}$}

The NSC was unable to obtain information on the source term through the emergency response support system (ERSS). Accordingly, to evaluate the exposure dose for local residents by using SPEEDI, the NSC has since March 17 been inversely estimating the temporal 
variation of the release amount based on the monitoring results and predicted information produced by SPEEDI. On March 23, the thyroid dose of radioiodine was evaluated and the results were utilized to select target areas for examining children for thyroid exposure.

The reverse estimation of the source term was performed due to a lack of data from the ERSS. However, it has not been verified whether quantitatively reliable results could be obtained using the functional ERSS in combination with SPEEDI. Thus, rather than conducting a quantitative assessment based on the ERSS, which has uncertain reliability, and a forecast produced by SPEEDI, other dose assessments based on a simple fitting of the monitoring data with the computational predictions as well as dose assessments based on the reverse estimation of the source term may prove more useful even if the assessment is made in near real-time or hindcast.

\section{Possible Utilization in the Future}

Before the main discussion, we summarize the circumstances during the accident. Venting operations began at Unit 1 about 18 hours after the earthquake, while Unit 1 experienced a hydrogen explosion about 24 hours after the earthquake. These intended or unexpected atmospheric releases took place during the evacuation of nearby residents. Meanwhile, the systematic implementation of emergency monitoring had to wait for 4 days until March 15. Soon after the earthquake, SPEEDI was started up on March 11 as the only source of timely information for making decisions concerning countermeasures and establishing plans for monitoring. Despite the prediction for the relative distribution demonstrating a certain degree of reliability as explained above, SPEEDI could not identify absolute values and provide sufficient information.

Given these circumstances, it is unlikely that monitoring or computational predictions alone could provide a necessary and sufficient amount of the information required to deal with any emergency from its onset, no matter how much quicker the emergency monitoring and inverse estimation of the source term could be performed. Comprehensive assessments should be strengthened by combining mutually complementary monitoring and computational predictions.

In light of the verification provided here, computational predictions can be utilized in the following ways by realizing their capacity to provide forecasts and immediately assess the overall situation.

(1) In the initial stage before an emergency monitoring system has been properly set up:

- Planning of emergency monitoring and evaluation of monitoring results based on the predicted atmospheric dispersion and ground deposition.

- Early-stage decision-making with regard to the necessary measures based on an assessment of the current situation by fitting the discrete monitoring values and a predicted distribution that assumes the release of a unit amount.

- Judgment concerning the timing of evacuations, sheltering, ingestion of stable iodine tablet, and the like based on prediction for incoming plumes.

- Judgment concerning the timing of venting and other planned releases based on the impact prediction.

(2) Once an emergency monitoring system is in place:

- Evaluation of the scale of the accident by reverse estimation of the source term and detailed exposure dose assessment. 
- Food inspection based on prediction for an extensive dispersion and facilitation of the surrounding communities to understand the processes by which hot spots are created.

Experts should be trained and become competent in both monitoring and computational predictions so that they can integrate their outcomes and extract useful information.

This commentary verifies the accuracy and timeliness of predictions produced by SPEEDI. It also proposes possible utilization for SPEEDI. The author hopes that the conclusions of this commentary will serve as a useful reference for the national and local governments when they draft manuals and other documents on nuclear emergency measures.

\section{References}

1) Fukushima Prefecture, http://www.pref.fukushima.jp/j/post-oshirase.pdf.

2) Nuclear Regulation Authority, http://www.bousai.ne.jp/speedi/SPEEDI_index.html.

3) Nuclear Regulation Authority, http://www.nsr.go.jp/archive/nisa/earthquake/speedi/erc/speedi_erc_ index.html.

4) Nuclear Regulation Authority, http://www.nsr.go.jp/archive/nisa/earthquake/speedi/ofc/speedi_ofc_ index.html.

5) Ministry of Education, Culture, Sports, Science and Technology, http://www.mext.go.jp/component/ a_menu/other/detail/_icsFiles/afieldfile/2012/07/26/1323887_01.pdf.

6) Nuclear Regulation Authority, http://www.nsr.go.jp/archive/nsc/mext_speedi/0312-0324_in.pdf. 